\title{
Resenha
}

\section{Saúde mental em assentamentos rurais no Rio Grande do Norte e no Piauí}

\author{
Rosineide Cordeiro ${ }^{\mathrm{I}}$
}

\footnotetext{
${ }^{\mathrm{I}}$ Professora do Departamento de Serviço Social e do Programa de Pós-graduação da Universidade Federal de Pernambuco. Pesquisadora dos estudos rurais, gênero e feminismo.
}

Condiçóes de vida e saúde mental em contextos rurais (Intermeios/FAPEPI/CNPQ/UFRN/UFPI, 2016, 428 páginas), com a organização de Magda Dimenstein, Jader leite, João Paulo Macedo e Cândida Dantas, é uma obra que mostra o acúmulo e o vigor dos/as pesquisadores/as nas áreas da saúde mental e dos assentamentos da reforma agrária.

O livro teve origem na pesquisa Condiçóes de vida e saúde mental em assentamentos rurais no nordeste brasileiro: diagnóstico, estratégias de cuidado e suporte na rede de atenção primária e psicossocial, que foi desenvolvida pelas Universidade Federal do Rio Grande do Norte e Universidade Federal do Piauí. Uma pesquisa de grande escopo foi realizada em nove assentamentos no Rio Grande do Norte e seis no Piauí, o que totalizou 1.106 famílias, 375 no RN e 731 no PI, perfazendo um total de 4.093 indivíduos. 67 profissionais que compóem as equipe de saúde e assistência social que prestam atendimento nos assentamentos foram entrevistados/as.

Para a coletânea, os/as organizadores/as convidaram estudiosos/as de outras áreas disciplinares (Agronomia, Geografia, Saúde Coletiva, Sociologia e Serviço Social), do Brasil e de Portugal, o que possibilitou um olhar mais ampliado sobre os dados da pesquisa e sobre o debate teórico a respeito da saúde mental, especialmente do uso abusivo do álcool, dos Transtornos Mentais Comuns (TCM), dos cuidados e das políticas de saúde e assistência em contextos rurais.

Ao se debruçarem sobre diferentes dimensões da saúde mental das populaçóes rurais assentadas, considero que os/as autores/as operaram no que Boaventura (2011, p. 30) denominou de sociologia das ausências, ao evidenciarem "que no existe es, de hecho, activamente producido como no-existente". Nesse lastro, elaboraram uma crítica contundente ao capitalismo no campo e seus efeitos na vida e na saúde das populações rurais. Categorias teóricas como determinações sociais da saúde, desigualdades, vulnerabilidades e iniquidades foram empregadas em diferentes capítulos, para fundamentar as análises sobre as injustas relaçôes sociais no campo, que têm como pilares a grande propriedade patronal, o agronegócio, a precariedade estrutural da agricultura camponesa e a instabilidade das situações vividas pelas populaçóes camponesas (WANDERLEY, 1996).

Avalio que os/as autores também manejaram a sociologia das emergências que, conforme Boaventura, "consiste em la investigación de las alternativas que caben en el horizonte de las posibilidades concretas (2011, p. 33)". Examinando diferentes aspectos da saúde mental e da assistência nos assentamentos rurais, os/as autores/as mostraram que é possível um vida justa, bela e decente para quem vive e trabalha com a terra. Um horizonte de possibilidades concretas foi problematizado. Tais possibilidades podem ser: a reforma agrária, políticas agrárias e os movimentos sociais rurais; os desafios ético-metodológicos da pesquisa qualitativa com populaçôes vulneráveis; a produção de cuidado na atenção básica em saúde; o território como princípio organizador dos cuidados; a construçấo de redes intersetoriais; a formação sistemática dos/as técnicos a partir dos princípios da educação popular em saúde.

A coletânea é organizada em sete eixos e cada um contém dois capítulos, com exceção do último, que tem três, perfazendo ao todo 15 capítulos.

O primeiro eixo é intitulado reforma agrária e condiçóes de vida em assentamentos rurais. O texto de Bernardo Fernandes $A$ importância da reforma agrária para o desenvolvimento do Brasil aborda a discussão paradigmática da reforma agrária e a situa como um campo de disputa socioterritorial, que envolve diferentes atores sociais. O capítulo de Sergio Sauer Luta pela terra e reforma agrária: a construção de espaços de cidadania no Brasil apresenta a concentração fundiária, as lutas por terra e os programas governamentais de reforma agrária.

A determinação social da saúde e da vida é discutida no segundo eixo. Adriana Loureiro, Claudia Costa e Paula Santana, em Determinantes contextuais da saúde mental, avaliam os determinantes contextuais e sua influência na saúde mental examinado os territórios urbanos e rurais. Victor Belarmino, Magda Dimenstein, Jader Leite, Joáo Paulo Macedo e Candida Dantas, 
em Território e determinação social da saúde mental em contextos rurais, abarcam o debate sobre as vulnerabilidades e determinaçôes sociais em saúde, para discutirem as especificidades da saúde mental nos assentamentos rurais pesquisados.

O terceiro eixo aborda os aspectos ético-políticometodológicos. O capítulo Desafios ético-metodológicos nas pesquisas em saúde mental com populaçôes vulneráveis, de Maria Lucia Magalhaes Bosi e Iara Coelho Zito Guerreiro, discute os desafios ético-metodológicos nas pesquisas qualitativas. No texto Aspectos metodológicos da pesquisa em contextos rurais" de Jaqueline Torquato, Magda Dimenstein, Jader Leite, João Paulo Macedo et al. apresentam o delineamento metodológico da pesquisa, contextualizam os cenários investigados e os principais resultados.

Processos de subjetivaçáo em contextos de pobreza é priorizado no quarto eixo. Em Novos cenários da pobreza e da seca na zona rural nordestina: suas implicaçôes na saúde mental, Verônica Morais Ximenes, Carla Evelline de Sousa Camurça discutem a perspectiva multidimensional da pobreza para abordar o processo de saúde mental das populações rurais no semiárido nordestino e as particularidades históricas das iniquidades em saúde nesse território. No capítulo Condiçôes de vida no meio rural: iniquidades sociais e ambientais são debatidas as semelhanças e diferenças a respeito dos Transtornos Mentais Comuns (TCM) e do uso abusivo de álcool, pelos autores/as Monique Silva, Magda Dimenstein, Jáder Leite, João Paulo Macedo et al.

O quinto trata da Saúde Mental, Gênero e Vida no Campo. Valeska Zanello, em Saúde mental e dispositivo, situa o debate de gênero e problematiza a noção de dispositivo ao relacionar amoroso e materno para as mulheres; e o da eficácia na virilidade sexual e laborativa para os homens. A autora analisa os efeitos desses dispositivos na saúde mental de homens e mulheres. O trabalho Saúde mental, condiçóes de vida e gênero: transtornos mentais comuns em assentamentos rurais problematiza como as relaçóes de gênero afetam, de forma diferenciada e desigual, a produçáo do sofrimento e o acesso ao serviços de saúde de homens e mulheres rurais. São autores/as desse capítulo Eliane Silva, Magda Dimenstein, Jáder Leite, João Paulo Macedo, et. al.

O uso de álcool em assentamentos rurais é analisado no eixo seis. O capítulo de Telmo Mota Ronzani, Pedro Henrique Antunes da Costa, e Fernando Santana de Paiva, Fatores associados ao uso do álcool em assentamentos rurais, discute o uso de álcool e outras drogas nas populações rurais. Defende a necessidade de articular diferentes marcadores sociais e os contextos históricos e culturais nas políticas de saúde e assistência. No capítulo Padräo de consumo de álcool em assentamentos rurais nordestinos, o leitor/a encontrará o perfil dos/as assentados/ as que consomem álcool, as especificidades regionais e os desafios de cuidados para usuários de drogas em contextos rurais. Magda Dimnestein, João Paulo Macedo, Jáder Leite, Candida Dantas et al. são autores/as deste trabalho.

No último eixo, foram organizadas as reflexóes sobre a oferta de cuidados psicossociais no meio rural. Ana Elídia Torres e Silvio Yasui, no trabalho O campo e a atenção psicossocial: diálogos possiveis e uma experiência para refletir, apresentam os conceitos de cuidado, território e rede como elementos centrais para a atenção psicossocial e destacam a formação permanente e a perspectiva da educação popular em saúde como estratégias importantes para a cuidado em saúde. O capítulo de Lucia Cristina dos Santos Rosa e Cristovam Colombo Belfort Respostas do SUS e SUAS às demandas das populaçôes rurais na perspectiva do cuidados psicossocial analisa as respostas do Estado brasileiro diante das lutas das populaçóes rurais. O último capítulo Ordenamento da rede e oferta de cuidados psicossociais no meio rural se debruça sobre os resultados da pesquisa a respeito da oferta dos cuidados pelo SUS e SUAS nos assentamentos rurais, a partir das entrevistas com os profissionais que atuam nesses territórios

Trata-se de uma obra que se tornará referência obrigatória para os/as estudiosos/as, gestores e ativistas no âmbito dos estudos rurais e das políticas de saúde mental e assistência. Preenche um vazio importante, pois o tema é pouco tratado na literatura sobre saúde mental e também nos estudos sobre as ruralidades. Oferece subsídios imprescindíveis para que o direito à saúde e à assistência das populaçóes rurais sejam efetivados no cotidiano dos serviços e das políticas públicas.

\section{Referências}

DIMENSTEIN, M, LEITE, J, MACEDO, J P, DANTAS, C. (2016). Condiçóes de vida e saúde mental em contextos rurais. Sáo Paulo: Intermeios: Brasília: CNPq; Natal: UFRN; Teresina: UFPI; FAPEPI/CNPQ/ UFPI.

SANTOS, SB. (2011). Epistemologías del Sur. Utopía y Praxis Latinoamericana: Revista Internacional de Filosofía Iberoamericana y Teoría Social. Año 16. No 54, Maracaibo -Venezuela (Julio-Septiembre) pp.17-39. http://www.boaventuradesousasantos. pt/media/EpistemologiasDelSur_Utopia\%20y\%20 Praxis\%20Latinoamericana_2011.pdf. Capturado em 20 de outubro de 2016. 
WANDERLEY, M de NB. (1996). Raízes históricas do campesinato brasileiro. In: XX Encontro Anual da ANPOCS. GT 17. Processos Sociais Agrários. Caxambu, MG. Outubro.http://www. reformaagrariaemdados.org.br/sites/default/ files/Ra\%C3\%ADzes\%20Historicas\%20do\%20 Campesinato\%20Brasileiro\%20-\%20Maria\%20 de\%20Nazareth\%20Baudel\%20Wanderley $\% 20$ -\%201996.pdf Capturado em 22 de novembro de 2016. 